(1854), F.J. Huntington, New York, NY.

Butler, M.M. (ed.), Monographs on Education in the United States (1904), Louisiana Purchase Exposition Company, Albany, NY., p. 63.

Ferguson, James, An Easy Introduction to Astronomy for Young Gentlemen and Ladies (1817), Benjamin Warner, Lancaster, England.

Hinsdale, B.A., Horace Man and the Common School Revival in the United States (1900), Scribner's, New York, NY.

Hoff, Darrel B., et al., "Earth science teaching in Iowa during the decade 1976-1986," Journal of Geological Education, 36, 1988.

Noble, Stuart G., A History of American Education (1970), Greenwood Press, Westport, Connecticutt, p. 51.

Packer, Paul C., Housing of High School Programs (1924), Teachers College, Columbia University, New York, NY, pp. 8-9.

Weiss, Iris. Report of the 1985-86 National Survey of Science and Mathematics Education, Research Triangle Institute, November 1987.

Welch, Wagne L., et al. "How many are enrolled in science?" The Science Teacher, December, 1984.

Young, Charles A., Elements of Astronomy (1897), Ginn and Company, Boston, MA.

\title{
Discussion
}

C. Harper: The renewed interest in astronomy in the 1960's would seem to be correlated with the development of the U.S. space program.

\section{THE COMMITTEE OF TEN}

\section{Jeanne E. Bishop}

Director, Westlake Schools Planetarium, 24525 Hilliard Road, Westlake, Ohio 44145, U.S.A.

The college-educated populations of colonial 18th- and 19th-century United States were reasonably well-versed in principles of elementary astronomy - perhaps not fully in spatial concepts of seasons and lunar phases, though they certainly had some correct ideas about their causes. Astronomy had found a niche in academies and in the public high schools that succeeded them. In 1838 an observatory was installed in a Philadelphia high school. The states turned to the academies and early high schools for the majority of their elementary teachers, so the teachers who completed high school in the 19th century had been taught the reasons for common astronomical phenomena and conveyed these reasons to children. Parental 
teaching reinforced what was taught in primary schools. Until the late 19th century, colleges continued to offer astronomy or natural philosophy as part of the general curriculum. It therefore seems that a cycle of astronomy teaching and learning rudimentary astronomy was in effect until the late 1900 's.

What caused the decline and virtual omission of basic astronomy from U.S. elementary and secondary schools for over fifty years, from about 1900 to 1950 and on? I conclude that it was the work of "The Committee of Ten."

In 1892, Charles W. Eliot of Harvard and other college administrators became concerned with inconsistent preparation for college; they requested that conferences be held by small groups of designated college and high school instructors in each of nine subject areas. The purpose of each meeting was to make recommendations for what should be taught in high schools that would be accepted for college admission. The resulting reports, published in 1893 by the U.S. Bureau of Education, became known as "The Report of the Committee of Ten." 1.

One conference or committee was designated, "Physics, Astronomy, and Chemistry," but the group of invited chemistry and physics teachers (no astronomy or natural philosophy teachers or professors) immediately changed the name to "Physics, Chemistry, and Astronomy." No reason for the change was given. The rest of this group's decisions also reflected the position that astronomy was of minor importance compared with physics and chemistry.

This group's most influential decision for astronomy was item \#9 in its report: "That Astronomy be not required for admission to college." This followed "That Both Physics and Chemistry be required for admission to college." As with the name change, no rationale was provided for this set of declarations, such as those included with many of the important recommendations of the other subject conferences.

The "Physics, Chemistry, and Astronomy" conference was silent concerning what should be included in any astronomy course (if offered, the group said that it should be a 12-week elective) or unit offered in either high school or elementary school. In contrast, teams of researchers recommended 50 experiments for physics and 100 experiments for chemistry, which were printed with the conference report. The single astronomy teaching method advocated by the conference was \#12: "That the study of Astronomy should be by observation as well as by classroom instruction." In harmony with this statement and as evidence of the widespread high regard for the Report of the Committee of Ten, several laboratory astronomy texts appeared soon after the Report was published.

Often, it takes quite a while for educational reforms to occur after recommendations have been made. But this was not the case with the report of the Committee of Ten. Comparisons of the percentages of students enrolled in high school astronomy between 1890 and 1950 show a very fast decline in the late 1800 's and a slow continuing decline between 1915 and 1930, when the decline levelled off. The lack of recommendations for the study of astronomy in elementary school probably led to the disappearance of that subject from the elementary curriculum, except for what was taught about Earth motions under the heading of "Geography." The Geography subject conference did specify geography activities for elementary school, while 
the Natural History conference mapped out detailed elementary activities in botany and zoology.

I have concluded that the Committee of Ten orchestrated the disappearance of astronomy from U.S. schools and therefore from the common fund of knowledge. A review of astronomical knowledge of new college freshmen in 1940 showed that a large number of students did not know that the sun is a star, that the stars are farther apart than the Earth and sun, that the sun and stars move, that the planets move in noncircular orbits, that light takes time to travel through space, and that stars appear to move from east to west because of the Earth's rotation.

It seems that the Report of the Committee of Ten, whose precepts were followed in high schools, elementary schools, and colleges as if they were laws, was the cause of this chain of events: (1) Astronomy was dropped as a requirement for admission to college. (2) Students took chemistry and physics (and also biology), but not astronomy, since the former were required for college admission. (3) Astronomy was dropped from the list of courses of most high schools. (4) Astronomy was dropped from the list of required and offered courses in teacher-preparation institutions and many liberal arts colleges. (5) For over 60 years the average educated U.S. citizen largely was illiterate in astronomy .... In this period astronomy as a science was proliferating in leaps and bounds, and it was extremely exciting to those aware of the milestones: the source of solar and stellar energy, the extent of the Milky Way Galaxy, the existence of other galaxies, the expanding-universe interpretation of the red shift of galaxies, the birth of radio astronomy, and the dedication of the $5-\mathrm{m}$ (200-inch) Hale Telescope on Palomar Mountain. But very little information filtered down to either high schools or elementary schools. Texts did not cover these areas, and teacher-preparation courses did not include them.

This brief discussion raises some questions ... Why were there no astronomers on the "Physics, Chemistry, and Astronomy" committee in 1892? Why did the recommendations of the Report of the Committee of Ten have so much influence? How might the effect have been avoided or reversed? How did people learn any astronomy in this "Dark Age of Astronomy" (first half of the 20th century)? And why was there a Renaissance in astronomy education beginning about 30 years ago? I have presented some of my ideas on these elsewhere. ${ }^{2,3}$ I would welcome your insights on these questions, and on this topic generally.

${ }^{1}$ U.S. Bureau of Education. Report of the Committee on Secondary School Studies. Washington, D.C.: Government Printing Office, 1893.

${ }^{2}$ Bishop, Jeanne E. "United States Astronomy Education: Past, Present, and Future." Science Education 61 (3): 295-305 (1977).

${ }^{3}$ Bishop, Jeanne E. "Astronomy Education in the United States: Out from Under a Black Cloud." Griffith Observer. pp. 2-10. March, 1980.

\section{Discussion}

D. McNally: One should, perhaps, not be too hard on the "Committee of Ten." 
They may have been responding (unconsciously?) to a wider trend. For example, in the UK, after the great era of 19th century popularization of astronomy by people such as John Herschel, Agnes Clerke, and Procter, astronomy in the early 20th century rapidly disappeared from the formal science educational curriculum. This pattern also seems to have appeared in other parts of the English-speaking world albeit at different rates. A possible underlying reason may be the excitement in physics research at the turn of the century.

J.E. Bishop: I agree that the perceptions of the Committee on Physics, Chemistry, and Astronomy may have been the same as groups elsewhere. However, I do think that other close countries and regions were influenced by the Report of the Committee of Ten. Possibly well-educated nonastronomers thought of astronomy as it was some 20 years before - positional astronomy with world-valued activities for time-keeping, navigation, and surveying. Astrophysics, by 1892, was earning a place as a proper field of astronomy (with much done in the United States), but few knew about it. You are right: physics may have drawn away the excitement.

J.M. Pasachoff: The American Association for the Advancement of Science (1333 $H$ Street, NW, in Washington, DC) has launched a major program, Project 2061 (named after the date of the next visit from Halley's Comet), to improve science and mathematics education across all school grades. Entitled "Education for a Changing Future," panels have prepared interdisciplinary statements of the kinds of knowledge that may be necessary in the future. Section D (Astronomy) of the AAAS (Jay M. Pasachoff, Retiring Chair; Virginia Trimble, Chair; and Arthur Davidsen, ChairElect) are among those representing astronomy. We will try to see that astronomy fares better than it did with the Committee of Ten.

J.E. Bishop: It is important and admirable that the AAAS Project 2061 committee will work to avoid rejection of astronomy education in schools. I suggest that the group initiate and maintain channels of communication with school administrator organizations, teachers' organizations, and the National Science Foundation, which funds teacher workshops and programs. Hopefully scientist groups in other countries also will work with educational leaders and financial supporters to improve science and mathematics education generally and astronomy education particularly.

H.L. Neumann: Astronomy education may have declined late in the 1800s because outdoor illumination was increased, so fewer people needed astronomical knowledge for everyday life.

J.E. Bishop: It seems possible that some people felt so. . maybe even Committee of Ten members.

W. Osborn: This talk and the commentators have emphasized the importance of making one's views known when it comes to astronomy education. Our own statespecified curriculum in science for elementary schools is an example of what occurs when a committee specifies astronomy content in a curriculum without input from an astronomer or astronomy educator. 
J. Percy: Astronomers should not wait to be invited to serve on curriculum advisory boards and committees. They should invite themselves to become involved as soon as they know that such boards and committees exist.

J.E. Bishop: My reason for bringing this historical topic to the attention of the group is hope that awareness of it might motivate many to do exactly what Drs. Osborn and Percy recommend. Astronomers need to be better "cheerleaders" for their subject. I suggest these ways of becoming involved with pre-college science education: 1) offer to participate in programs or meetings for school administrators; 2) write enthusiastic articles about the nature and importance of science (with astronomy) for journals of school administrators, school boards, and educational regulation agencies; and 3) generally befriend and offer advisory support to officials in positions to make key educational decisions.

J.M. Pasachoff: In American colleges and universities, at least, physicists often think that they can properly teach astronomy, and astronomy sometimes is forced to take a junior role in joint departments of physics and astronomy. Physicists, however, usually lack the breadth of astronomical experience to be able to tie together celestial topics from an astronomical point of view. Further, when astronomers lose their independence, their access to university administration and to funding is diminished. I feel that the smaller the department, the more important it is for the astronomers to be independent. After all, a relatively large group of astronomers can defend themselves. We astronomers should be emphasizing that astronomy is a separate science from physics, and that astronomy departments should be independent.

\section{SCIENCE TEACHING THROUGH ITS ASTRONOMICAL ROOTS}

Philip M. Sadler and William M. Luzader, Project STAR, Harvard-Smithsonian Center for Astrophysics, 60 Garden Street, Cambridge, Massachusetts 02138 U.S.A.

\section{Introduction}

Project STAR (Science Teaching through its Astronomical Roots) emerged from growing concern about the decreasing enrollment in science classes, and lack of understanding of science and math concepts ${ }^{1}$ (Figure 1). Using astronomy as a focus, Project STAR is trying not simply to increase the enrollment in high school science courses, but also to improve the students' understanding of science and its role in making sense of the world. 